\title{
Gas-exchange Measurements using a Large, Closed Plant Growth Chamber
}

\author{
Raymond M. Wheeler \\ National Aeronautics and Space Administration Biological Operations and Life Support, Mail Code MD-RES, \\ Kennedy Space Center, FL 32899
}

Plant-growth chambers vary widely in size and capabilities (Downs, 1975), but regardless of size, several criteria must be met if a plant chamber is used for photosynthetic gas-exchange measurements. In general, the chamber must be tightly closed with a known volume (closed system), or the chamber can be open but with a measured air flow passing through it (open system; Mitchell, 1992). In closed systems, photosynthesis can be determined either by the drawdown rate of $\mathrm{CO}_{2}$ in the chamber (i.e., a true closed system), or from the mass of $\mathrm{CO}_{2}$ injected into the chamber to balance photosynthetic uptake by plants (semiclosed system). In open systems, photosynthetic rate is determined by the difference in $\mathrm{CO}_{2}$ between air entering the chamber and air leaving the chamber (Coombs et al., 1985; Mitchell, 1992).

Closed-system approaches typically have been used with smallsized plant growth chambers: $2.38 \mathrm{~m}^{3}$ (Acock et al., 1977); 0.73 $\mathrm{m}^{3}$ (Andre et al., 1985); $0.19 \mathrm{~m}^{3}$ (Dutton et al., 1988); $0.3 \mathrm{~m}^{3}$ (Knight et al., 1988); $0.20 \mathrm{~m}^{3}$ (Schwartzkopf and Stofan, 1981) (see also Bazzaz and Boyer, 1972). However, moderate and largesized closed growth chambers have been built: $300 \mathrm{~m}^{3}$, including a human habitat (Gitel'son et al., 1989); $9.9 \mathrm{~m}^{3}$ (Hand, 1973b); $15.4 \mathrm{~m}^{3}$ (Musgrave and Moss, 1961); $113 \mathrm{~m}^{3}$ (Prince et al., 1987). A large closed system is currently operated by the U.S. National Aeronautics and Space Administration (NASA) at the Kennedy Space Center, Fla. The chamber, called the Biomass Production Chamber (BPC), was built for NASA's Controlled Ecological Life Support System (CELSS) program (Averner, 1989; Prince and Knott, 1989). One aspect of the CELSS program emphasizes the use of higher plants to provide food, $\mathrm{O}_{2}$, and potable water for humans during prolonged space habitation; the plants, in turn, could be used to recycle waste $\mathrm{CO}$, and minerals from the human habitation modules (Averner, 1989; MacElroy and Bredt, 1985). Thus, a need arose for NASA to initiate large-scale testing to quantify biomass production, mass balance, and any contaminant build-up that might occur in a tightly sealed plant-growth system.

Chamber description. The BPC is a cylindrical steel chamber (7.5 $\mathrm{m}$ high and $3.7 \mathrm{~m}$ in diameter; Fig. 1) that formerly was used for hypobaric tests during NASA's Mercury Project (Prince et al., 1987). In its current configuration, the chamber is divided into two levels with two plant-growth shelves per level (Prince et al., 1987). Each shelf can support up to sixteen $0.25-\mathrm{m}^{2}$ plastic hydroponic culture trays. After accounting for gaps between trays, $\approx 5 \mathrm{~m}^{2}$ per shelf, or a total area of $20 \mathrm{~m}^{2}$, is available to grow plants.

The chamber is equipped with 96 (48 per level) 400-W highpressure sodium lamps with remote dimming ballasts. Each level has a $30-\mathrm{kW}$ fan for air circulation along with a cold-water heat exchanger for cooling and dehumidification, a hot-water heat exchanger for temperature control, a coarse particulate filter, and a 0.3- $\mu \mathrm{m}$ high-efficiency particulate air (HEPA) filter (Fig. 1). Cold water for heat removal is provided by two $53-\mathrm{kW}$ (two 15-ton) chilling units and hot water by a $150-\mathrm{kW}$ heater (Sager et al., 1988). Fans provide from three to four volume changes per minute $(400$ to $\left.450 \mathrm{~m}^{3} \cdot \mathrm{min}^{-1}\right)$, with air velocities at the plant level ranging from 0.2 to $1.5 \mathrm{~m} \cdot \mathrm{s}^{-1}$. Chamber volume, including the air handling system, is $\approx 113 \mathrm{~m}^{3}$ (Sager et al., 1988). More thorough descriptions of subsystem design and control of NASA's BPC can be found in Prince and Knott (1989), Prince et al. (1987), and Sager et al. (1988). It is important to note that the current design is only an initial approach to study crop growth in a closed system and is not

Received for publication 22 July 1991. The cost of publishing this paper was defrayed in part by the payment of page charges. Under postal regulations, this paper therefore must be hereby marked advertisement solely to indicate this fact. meant to represent the final configuration that would be used in space.

Gas monitoring and control systems. Carbon dioxide concentrations within each level of the BPC are monitored and controlled with infrared gas analyzers (model AR-203; Anarad, Santa Barbara, Calif.); a third analyzer, which samples both levels, is used strictly for redundant monitoring (Sager et al., 1988). Signals from the two control $\mathrm{CO}_{2}$ analyzers, along with those from other environmental sensors, are processed by a programmable logic controller (Reliance Electric Corp., Stone Mountain, Ga.). Signals from the monitoring analyzer are averaged and logged at 5-min intervals through a datalogging interface (Opto-22; Optomux, Huntington Beach, Calif.) to a 386 PC computer. Carbon dioxide is added to the chamber through four supply lines (two for each level) and measured with mass-flow sensors (model 5860; Brooks Instruments, Hatfield, Pa.). Analog signals from the flow sensors are summed with integrators (model 1752-G-KO-1-C, Acromag, Wixom, Mich.) and then logged with the PC. If needed, $\mathrm{CO}_{2}$ added to the chamber can first pass through a column of potassium permanganate-coated alumina pellets (Air Repair, Stafford, Texas) to remove contaminants, e.g., ethylene (Eastwell et al., 1978; Knight, 1992; Morison and Gifford, 1984).

Oxygen concentrations are monitored with two fuel-cell-type detectors $\left(0.1 \%\right.$ resolution) plumbed in series with the $\mathrm{CO}_{2}$ analyzers used for control, while a third, solid oxide (stabilized-zirconia) $\mathrm{O}_{2}$ analyzer $(0.01 \%$ resolution, model S-3A/l; Ametek, Pittsburgh) is used for redundant monitoring. Once each day, all $\mathrm{CO}_{2}$ and $\mathrm{O}_{2}$ analyzers are automatically calibrated with standard gases to update computer-conversion equations.

\section{Photosynthetic gas-exchange measurements}

With the capability to measure either $\mathrm{CO}_{2}$ mass flow (during steady-state operation) or $\mathrm{CO}_{2}$ drawdown rates when the external $\mathrm{CO}_{2}$ supply has been shut off, the BPC can be operated either as a

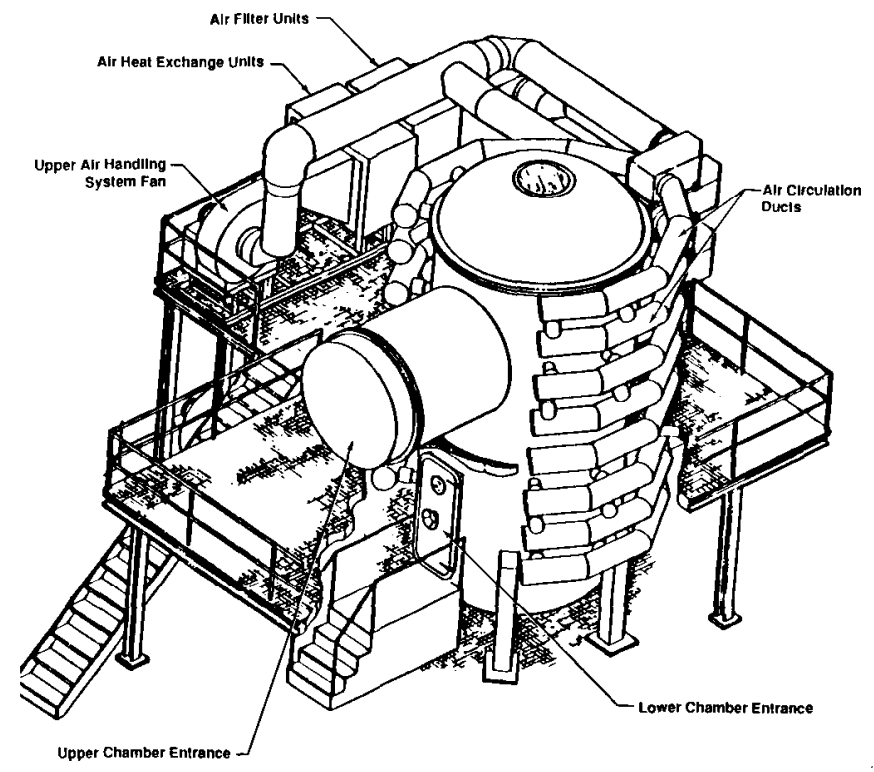

Fig. 1. Diagram of the Biomass Production Chamber used for plant growth and gas-exchange tests for NASA's Controlled Ecological Life Support System program. The cylindrical, steel chamber is $7.5 \mathrm{~m}$ high and $3.7 \mathrm{~m}$ in diameter and has a total internal volume (including air ducts) of 112.6 $\mathrm{m}^{3}$ and $\approx 20 \mathrm{~m}^{2}$ area for plant growing. Plants are grown in hydroponic trays supported on four shelves within the chamber. Lighting is provided with ninety-six 400-W high-pressure sodium lamps. 
semiclosed or a closed gas-exchange system (Mitchell, 1992). By knowing chamber volume and directly measuring stand area, the only remaining requirement is that the chamber be closed. To test for closure, $\mathrm{CO}_{2}$ concentration in the chamber (while empty of plants) can be raised and the decay rate from leakage monitored (Acock and Acock, 1989; Sager et al., 1988). Under isothermal conditions, leakage typically ranges from $5 \%$ to $10 \%$ of the chamber volume per day (Wheeler et al., 1991). This rate compares favorably with leakage rates reported for much smaller, closed plantgrowth systems: $12 \%$ to $48 \%$ of volume per day (Hand, 1973b); $48 \%$ to $240 \%$ of volume per day (Acock et al., 1977); $4 \%$ of volume per day (Schwartzkopf and Stofan, 1981). Initial plant tests showed that sufficient data for calculating photosynthetic rates can be gathered in $1 \mathrm{~h}$ or less; thus, no more than $10 \%$ per $24 \mathrm{~h}$, or $0.4 \%$ of the volume, would be leaked during a 1-h measurement.

As with all closed systems, gas leakage from the BPC is directly affected by the internal/external pressure gradient (Hand, 1973a). Thus, any factors that affect pressure also affect leakage. For example, changing the chamber temperature from 26C (day) to $20 \mathrm{C}$ (night) causes a pressure decrease (partial vacuum) within the system, while the opposite (pressure increase) occurs by increasing the temperature from 20 to $26 \mathrm{C}$ (Fig. 2). In each case, return of pressure to the normal, near-zero operating state after the temperature stabilized indicates that mass leakage has occurred (Fig. 2). The volume (V) change (i.e., leakage) in response to a temperature (T) change can be estimated by applying Gay-Lussac's Law (Charles' Law) (Barrante, 1977): $\mathrm{V}_{1} / \mathrm{T}_{1}=\mathrm{V}_{2} / \mathrm{T}_{2}$ or $\mathrm{V}_{2}=\left(\mathrm{V}_{1} \mathrm{~T}_{2}\right) / \mathrm{T}_{1}$. Then for a $6 \mathrm{~K}$ increase in the BPC: $V_{2}=\left(112.6 \mathrm{~m}^{3}\right)(299 \mathrm{~K}) /(293 \mathrm{~K})$; $\mathrm{V}_{2}=114.9 \mathrm{~m}^{3}$. The amount leaked then would equal $\mathrm{V}_{2}-\mathrm{V}_{1}=$ $114.9 \mathrm{~m}^{3}-112.6 \mathrm{~m}^{3}=2.3 \mathrm{~m}^{3}$. This amounts to $\approx 2 \%$ of the chamber volume leaked simply from the $6 \mathrm{C}$ temperature change. When a positive pressure develops inside the chamber, the excess volume is leaked outward and thus the relative concentrations of gases inside the chamber remain the same. However, when a negative pressure develops, the leakage is inward, causing a mixing of internal gases with atmosphere surrounding the chamber.

According to the combined gas law, PV = nRT (Barrante, 1977), two approaches might be used to reduce pressure events, and hence leakage, in response to temperature changes: 1) The system volume (V) could be allowed to change as temperature (T) changes; this might be accomplished by adding an expandable atmospheric reservoir to the system [e.g., bellows or bladder (Hand, 1973a)]. Or 2) mass (n) and pressure $(\mathrm{P})$ might be partitioned between the main

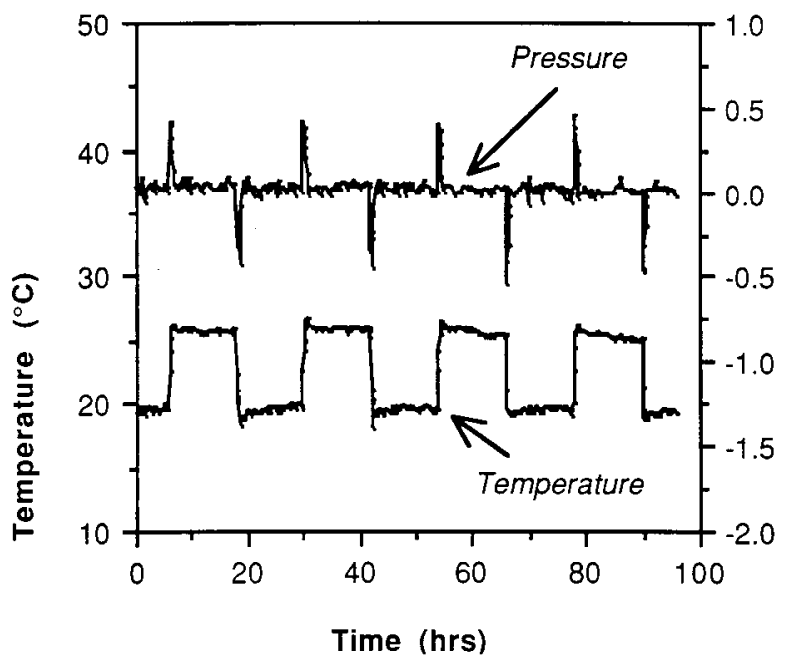

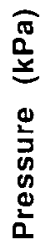

Fig. 2. Effect of diumal temperature changes on the internal/external atmospheric pressure gradient in NASA's Biomass Production Chamber. Because the volume is fixed, changes in temperature cause changes in pressure. The graph shows a repeating 12 -h thermoperiod of $26 \mathrm{C} / 20 \mathrm{C}$ with corresponding pressure spikes ranging between 0.5 and $1.0 \mathrm{kPa}$. Temperature changes of $6 \mathrm{C}$ typically require $\approx 15 \mathrm{~min}$ to complete. Pressure spikes decay quickly because of mass leakage inward during negative episodes (i.e., cooling) and leakage outward during positive episodes (i.e., heating). system and a low-leakage reservoir to offset changes in T; this could be accomplished by mechanically compressing gas during positive pressure spikes and releasing compressed gas during negative pressure spikes (J.C. Sager, unpublished). An active pressure control system employing a compressor is currently being used for the BPC.

In addition to affecting leakage, pressure changes also directly affect gas analyzers that are sensitive to gas densities (Jarvis and Sandford, 1985). Episodes of increased pressure will increase gas densities in the detector cells, thereby causing an apparent increase in concentration, while epidoses of reduced pressure will cause an apparent decrease. If pressure and temperature of the detector cells can be monitored accurately, appropriate corrections can be applied (Jarvis and Sandford, 1985). Otherwise, it is advisable to avoid periods of pressure change for calculating gas-exchange rates and calibration of analyzers. Similarly, any changes in water vapor pressure (absolute humidity) within the system will affect system leakage and will proportionately change the concentrations of other gases in the atmosphere. For example, if air is cooled from 26 to $20 \mathrm{C}$ while the relative humidity is held constant at $70 \%$, the pressure of water vapor (absolute humidity) drops $\approx 0.7 \mathrm{kPa}$. This will cause a proportionate increase of $0.7 \mathrm{kPa} / 101.3 \mathrm{kPa}$, or $\approx 0.7 \%$, in the other gases in the atmosphere. These effects can be avoided by keeping the water vapor pressure constant throughout the day; but this might be difficult to attain depending on chamber capabilities and the range of thermoperiods imposed. Thus, as with atmospheric pressure changes, one must either correct for the change in water vapor pressure (von Cammerer and Farquhar, 1981), or avoid periods of humidity change when calculating rates of gas exchange. Alternatively, the sample streams can be desiccated or brought to some constant absolute humidity before they enter the gas detectors. In the case of the BPC, all gas-analysis streams are passed through a cold coil $(2 \mathrm{C})$ to keep water pressure constant at $0.7 \mathrm{kPa}$.

Closed-system measurements. During operation of the $\mathrm{BPC}, \mathrm{CO}_{2}$ must be added from an external source to compensate for photosynthetic uptake by the plants. Consequently, true closed-system measurements, which are determined from drawdown rates after the $\mathrm{CO}_{2}$ supply has been shut off, can only be short-term events. An example of a complete drawdown of $\mathrm{CO}_{2}$ by a stand of wheat (Triticum aestivum L.) in the BPC is shown in Fig. 3. As might be expected for a $\mathrm{C} 3$ species, the drawdown shows an initial linear portion of the response curve, suggesting that the $\mathrm{CO}_{2}$ uptake is saturated at the higher $\mathrm{CO}_{2}$ concentrations. At lower concentrations, the curve asymptotically approaches the compensation point as $\mathrm{CO}_{2}$ becomes increasingly limiting (Hand, 1973a). By taking the first derivative of closed-system drawdowns, a complete response curve of photosynthetic rate vs. $\mathrm{CO}_{2}$ concentration can be generated from a single test (Fig. 3) (McDermitt et al., 1989; Wheeler and Sager, 1990).

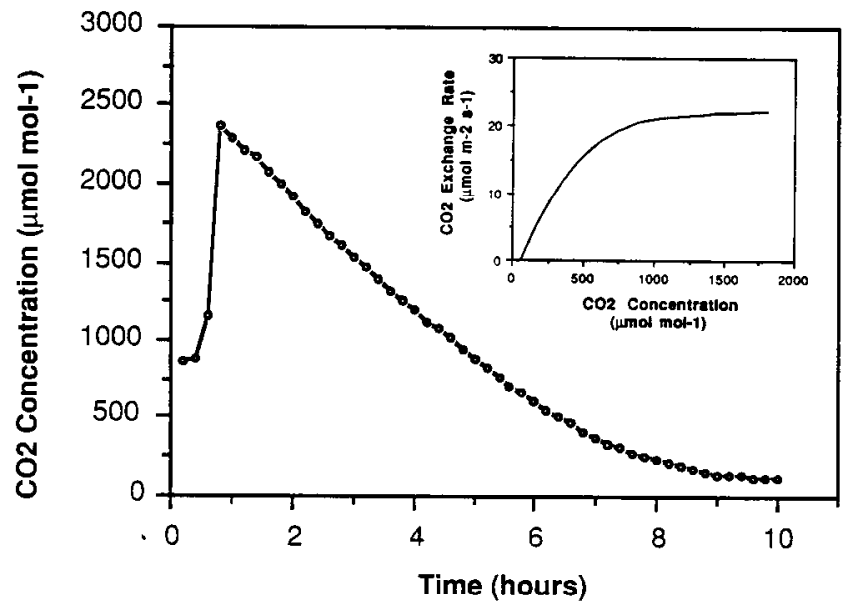

Fig. 3. Drawdown of $\mathrm{CO}_{2}$ by a stand of wheat. Little change in the rate (slope) of drawdown is apparent at high $\mathrm{CO}_{2}$ concentrations (e.g., $>1000$ $\mu \mathrm{mol} \cdot \mathrm{mol}^{-1}$ ). Below $700 \mu \mathrm{mol} \cdot \mathrm{mol}^{-1}$, the slope gradually decreases, asymptotically approaching the compensation point, at which no net $\mathrm{CO}_{2}$ uptake occurs. A plot of the drawdown rate (slope) as a function of $\mathrm{CO}_{2}$ concentration is shown in the inset. 
As with any closed gas-exchange system, tests should be conducted to verify that $\mathrm{CO}_{2}$ is not changing at a rate faster than that to which the plants are able to adjust (e.g., to allow stomatal adjustment to the changing $\mathrm{CO}_{2}$ concentrations). McDermitt et al. (1989) have shown that single leaves of well-watered, soybean [Glycine $\max \left(\mathrm{L}\right.$.) Merr.] plants were capable of adapting to $\mathrm{CO}_{2}$ drawdown rates as high as $1 \mu \mathrm{mol} \cdot \mathrm{mol}^{-1} \cdot \mathrm{s}^{-1}$. The most rapid drawdowns encountered with canopy tests in the BPC have been near $0.1 \mu \mathrm{mol} \cdot \mathrm{mol}^{-1} \cdot \mathrm{s}^{-1}$ (Fig. 3); thus, drawdown rates in the BPC should be sufficiently slow to allow plants to continually adjust to changing $\mathrm{CO}_{2}$ concentrations. In addition, comparisons of photosynthetic rates in the BPC using $\mathrm{CO}_{2}$ mass flow (i.e., semiclosed) measurements and closed-system drawdown rates have given similar results (Corey, 1989).

A convenient opportunity to use closed-system calculations occurs when the plants are grown under cycling photoperiods. If no steps are taken to suppress $\mathrm{CO}_{2}$ from rising above the set point, e.g., by dilution (Sager et al., 1988) or selective $\mathrm{CO}_{2}$ scrubbing (Gerbaud et al., 1988), $\mathrm{CO}_{2}$ concentrations will increase during dark periods from plant stand respiration. When the lamps are turned on, $\mathrm{CO}_{2}$ will draw back down to the set point, where controlled additions of $\mathrm{CO}_{2}$ begin (Acock and Acock, 1989). An example of repeating nocturnal rise and "morning" drawdown is shown for a stand of soybeans in Fig. 4. By measuring the slope of these diurnal changes, one can calculate stand respiration and photosynthesis. This procedure assumes, however, that the photosynthetic rate measured soon after the lamps come on is representative of the rate throughout the day, and this should be tested for each crop and each set of conditions. Typically, we avoid using the first $30 \mathrm{~min}$ of the morning drawdown when calculating gas-exchange rates. If "dark-period" respiration is to be used as an estimate of "dark" respiration during the light cycle, the difference between day and night temperature must be taken into account (Amthor, 1989).

Closed-system measurements of $\mathrm{O}_{2}$ concentrations also can be used to calculate photosynthesis. Because $\mathrm{O}_{2}$ resolution with present on-line detection systems is much lower than with the $\mathrm{CO}_{2}$ detectors, longer durations of complete closure are required to obtain sufficient data to calculate exchange rates, and correcting for leakage becomes more critical. An example of an $\mathrm{O}_{2}$ concentration increase during $48 \mathrm{~h}$ of closure of the BPC is shown in Fig. 5 for a soybean crop. In this case, $\mathrm{O}_{2}$ decreased $\approx 0.1 \%$ during the dark cycle from respiration and increased nearly $0.5 \%$ during the light from photosynthesis, yielding a net gain of $\approx 0.4 \% \mathrm{O}_{2} /$ day. To date, no efforts have been made to suppress $\mathrm{O}_{2}$ build-up in the BPC because the chamber is seldom closed for more than 72 to $96 \mathrm{~h}$ to accommodate entrance for plant cultural activities and systems

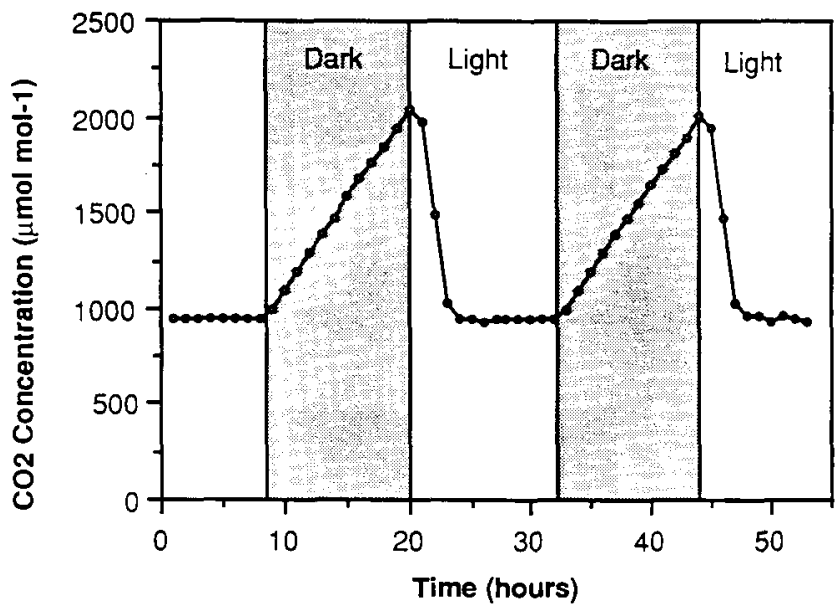

Fig. 4. Diurnal pattern of $\mathrm{CO}_{2}$ concentration with a soybean crop. During light periods, $\mathrm{CO}_{2}$ is added to offset photosynthetic uptake, and during the dark period, $\mathrm{CO}_{2}$ accumulates from respiration. When the lamps are turned on, photosynthesis quickly draws $\mathrm{CO}_{2}$ back down to the 1000 $\mu \mathrm{mol} \cdot \mathrm{mol}^{-1}$ set point, at which controlled $\mathrm{CO}_{2}$ additions begin. The slopes of the night increase and the morning drawdown can be used to track stand respiration and photosynthesis. maintenance. When the doors are opened, $\mathrm{O}_{2}$ levels quickly equilibrate with the ambient atmosphere. Oxygen-control systems that support long-duration closures to prevent potential fire hazards and minimize $\mathrm{O}_{2}$ suppression of photosynthesis in $\mathrm{C} 3$ crops have been studied (Schwartzkopf and Stofan, 1981).

Semiclosed system measurements. Semiclosed systems are desirable when it is important to monitor plant gas exchange under steadystate conditions, i.e., without a changing background $\mathrm{CO}_{2}$ concentration (Coombs et al., 1985; Mitchell, 1992). Unlike short-term drawdown estimates, continuous semiclosed measurements provide a direct measure of $\mathrm{CO}_{2}$ added over time and can be used to track any diurnal changes in photosynthetic rate (e.g., from endogenous stomata1 rhythms). In addition, the change in plant biomass can be estimated directly by measuring the amount of $\mathrm{CO}_{2}$ fixed (CharlesEdwards et al., 1986; Wheeler and Sager, 1990). However, when using a long-term mass-balance approach, total leakage rates, including periods of pressure change and chamber openings, must be included in the calculation.

An example of $\mathrm{CO}_{2}$ addition during a 48-h cycle for a stand of soybeans grown with a 12-h photoperiod is shown in Fig. 5. In this case, the rate of $\mathrm{CO}_{2}$ addition was linear across the light period, indicating a constant photosynthetic rate (Fig. 5). Note that $\mathrm{CO}_{2}$ addition did not start immediately after the lamps came on, but began only after $\mathrm{CO}_{2}$ accumulated from night respiration had been drawn down to the set point-about $2 \mathrm{~h}$ into the light period.

Measurements of transpiration and atmospheric contaminants

Supplemental humidification in the BPC is needed only when plants are very small and total transpiration is low (e.g., beginning of batch plantings). Humidification is accomplished by directly injecting a mist of deionized water into the air ducts. At all other times, typically 10 to 15 days after planting, humidifiers are deactivated and the chamber atmosphere must be dehumidified (Prince et al., 1987). Water vapor is removed from the atmosphere as condensation on the cold water coils of the heat-exchange systems and stored in a stainless steel reservoir. The condensate production provides a direct measure of stand evapotranspiration. Measurements have shown that direct evaporation from the existing hydroponic culture systems can be substantial when no plants are present-up to 30 liters $\cdot$ day $^{-1}$ (Wheeler et al., 1991). However, as the stand develops and full canopy cover is established, transpiration becomes the dominant source of water in the system. Currently, condensate tank volumes are monitored and emptied manually, but modifications are scheduled to provide continuous monitoring of volume

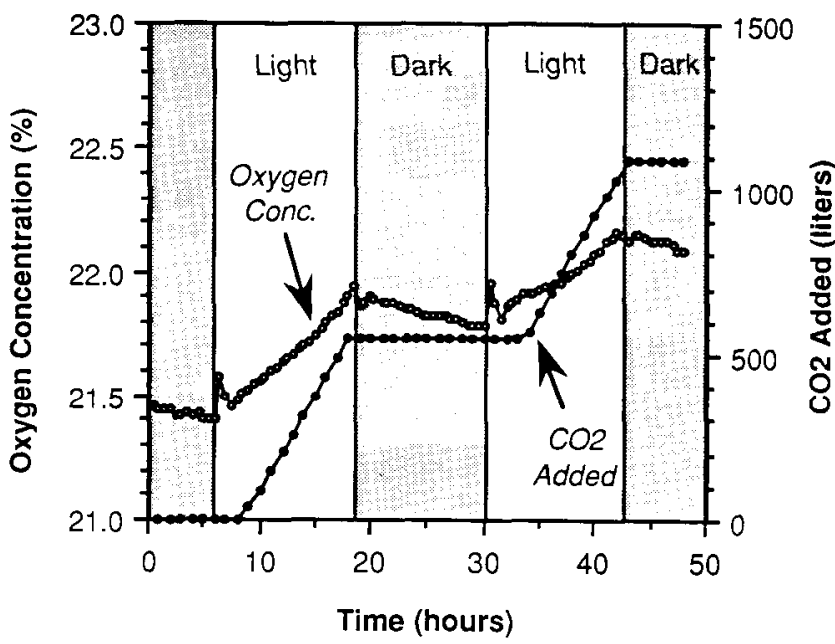

Fig. 5. Effect of $48 \mathrm{~h}$ of closure on the production of $\mathrm{O}_{2}$ and assimilation of $\mathrm{CO}_{2}$ by a stand of soybean plants. Carbon dioxide addition began only after excess $\mathrm{CO}_{2}$ from dark-period respiration had been consumed $(\approx 2 \mathrm{~h}$ after lamps on). An apparent spike in $\mathrm{O}_{2}$ concentration occurred immediately after the dark period, when the chamber temperature changed from 20 to $26 \mathrm{C}$, but this was likely a result of a transient atmospheric pressure $(\approx 1.0 \mathrm{kPa})$ event. The reverse (i.e., a dip) is apparent after the light period, when the temperature was lowered back to $20 \mathrm{C}$. In this case, a negative pressure of $\approx 0.8 \mathrm{kPa}$ developed. 
with pressure transducers positioned inside the storage tanks.

As with $\mathrm{CO}_{2}$ exchange, transpiration from plant stands is greatly influenced by environmental conditions. In particular, any factors that affect the transpiration potential (i.e., water vapor pressure deficit) and the resistance to transpiration (e.g., $\mathrm{CO}_{2}$ and photoperiod effects on stomata) are especially important. About 100 to 120 liters of water/day ( 5 to 6 liters $\cdot \mathrm{m}^{-2} \cdot \mathrm{day}^{-1}$ ) can be condensed from actively growing wheat and soybean stands in the BPC when $\mathrm{CO}_{2}$ is maintained at $1000 \mu \mathrm{mol} \cdot \mathrm{mol}^{-1}$ and the vapor pressure deficit is near $1.0 \mathrm{kPa}$ (Wheeler et al., 1990). Because $\mathrm{CO}_{2}$ is soluble in water, some $\mathrm{CO}_{2}$ will leave the system with the condensate, if the water is not immediately recycled to the nutrient solutions. With a solubility factor of $0.9 \mathrm{ml} \cdot \mathrm{ml}^{-1}$ at $20 \mathrm{C}$ (Forsythe, 1969) and a $\mathrm{CO}_{2}$ concentration of $1000 \mu \mathrm{mol} \cdot \mathrm{mol}^{-1}$, up to $0.9 \mathrm{ml}$ of $\mathrm{CO}_{2}$ could be dissolved in each liter of condensate water, or 100 liters.day ${ }^{-1} \times 0.9 \mathrm{ml} \cdot$ liter $^{-1}=90 \mathrm{ml}$ of $\mathrm{CO}_{2} /$ day. However, with actively growing stands requiring more than 500 liters of $\mathrm{CO}_{2} /$ day (Fig. 5), this loss and its effects on photosynthesis calculations can be ignored (for further discussion, see Bugbee, 1992).

In addition to capabilities for measuring $\mathrm{CO}_{2}, \mathrm{O}_{2}$, and $\mathrm{H}_{2} \mathrm{O}$ exchange, capabilities exist to regularly sample the chamber atmosphere for volatile hydrocarbons (e.g., ethylene) using gas chromatography with flame ionization and photoionization detectors (model 5880A: Hewlett Packard, Avondale, Pa.; model 10550: Photovac, Thornhill, Ontario). Capabilities also exist to begin characterizing the chamber atmosphere for organic contaminants using gas chromatography (Hewlett Packard model 5890) with a massselective detector (Hewlett Packard model 5970B).

\section{Summary}

The BPC was developed to study crop growth for human life support for NASA's CELSS program. The chamber provides $\approx 20$ $\mathrm{m}^{2}$ of growing area with $113 \mathrm{~m}^{3}$ of atmospheric volume in a tightly closed system. Because of its high degree of closure $(\approx 5 \%$ to $10 \%$ of volume leaked per day), photosynthetic uptake of $\mathrm{CO}_{2}$ and production of $\mathrm{O}_{2}$ can be tracked closely. Crop photosynthesis can be measured either by a semiclosed system approach, where mass flow of $\mathrm{CO}_{2}$ (from an external source) to balance photosynthetic uptake is measured, or by a closed-system approach, where the rate of $\mathrm{CO}$ drawdown can be tracked during periods when external $\mathrm{CO}_{2}$ is not supplied. Mass-flow measurements offer the advantage of tracking crop photosynthesis at steady-state $\mathrm{CO}_{2}$ concentrations, while closedsystem measurements offer the opportunity to quickly conduct total $\mathrm{CO}_{2}$ drawdown tests, providing complete response curves of photosynthetic rate vs. $\mathrm{CO}_{2}$ concentration. With present control capabilities, only closed-system calculations can be used to track the rate of $\mathrm{O}_{2}$ evolution from photosynthesis, and the rates of $\mathrm{CO}_{2}$ increase and $\mathrm{O}_{2}$ decrease from respiration during dark periods. Rates of evapotranspiration can be measured from condensate water collected below the cold coils of the air heat-exchange system and capabilities exist to sample chamber atmosphere for hydrocarbons and other volatile organic compounds throughout crop growth tests.

\section{Literature Cited}

Acock, B. and M.C. Acock. 1989. Calculating air leakage rates in controlled-environment chambers containing plants. Agron. J. 81:619-623.

Acock, B., D.A. Charles-Edwards, and A.R. Hearn. 1977. Growth response of a chrysanthemum crop to the environment. I. Experimental techniques. Ann. Bot. 41:41-48.

Amthor, J.S. 1989. Respiration and crop productivity. Springer-Verlag, New York.

Andre, M., A. Daguenet, D. Massimino, and A. Gerbaud. 1985. The $\mathrm{C}_{2} 3 \mathrm{~A}$ system, an example of quantitative control of plant growth associated with a data base. CELSS 85 Workshop, NASA Tech. Memoran. 88215, Moffett Field, Calif. p. 55-64.

Averner, M.M. 1989. The CELSS research program: A brief overview of recent activities, p. 145-153. In: D.W. Ming and D.L. Henninger (eds.) Lunar base agriculture. Amer. Soc. Agron.; Madison, Wis.

Barrante. J.R. 1977. Physical chemistry for the life sciences. Prentice-Hall, Englewood Cliffs, N.J.

Bazzaz, F.A. and J.S. Boyer. 1972. A compensating method for measuring carbon dioxide exchange, transpiration, and diffusive resistance of plants under controlled environmental conditions. Ecology 53:343-349.

Bugbee, B. 1992. Steady-state canopy gas exchange: System design and operation. HortScience 27:770-776.
Charles-Edwards, D.A., D. Doley, and G.M. Rimmington. 1986. Modelling plant growth and development. Academic, Sydney.

Coombs, J., D.O. Hall, S.P. Long, and J.M. O. Scurlock. 1985. Techniques in bioproductivity and photosynthesis. Pergamon Press, Oxford.

Corey, K.A. 1989. Dynamics of carbon dioxide exchange of a wheat community grown in a semi-closed environment, p. 58-84. In: E.R. Hosler and D.W. Amstrong (eds.). NASA/ASEE fellowship program: 1989 Research reports. Contractor Rpt. CR-166837, Kennedy Space Center, Fla.

Downs, R.J. 1975. Controlled environments for plant research. Columbia University Press, New York.

Dutton, R.G., J. Jiao, M.J. Tsujita, and B. Grodzinski. 1988. Whole plant $\mathrm{CO}$, exchange measurements for nondestructive estimation of growth Plant Physiol. 86:355-358.

Eastwell, K.C., P.K. Bassi, and M.E. Spencer. 1978. Comparison and evaluation of methods for the removal of ethylene and other hydrocarbons from air for biological studies. Plant Physiol. 62:723-726.

Forsythe, W.E. 1969. Smithsonian physical tables. 9th ed. Smithsonian Institution Press, Washington, D.C.

Gerbaud, A., M. Andre, and C. Richaud. 1988. Gas exchange and nutrition patterns during the life cycle of an artificial wheat crop. Physiol. Plant. 73:471-478.

Gitel'son, I.I., I.A. Terskov, B.G. Kovrov, G.M. Lisovskii, Y.N. Oklandnikov, F.Y. Sid'ko, I.M. Trubachev, M.R. Shilenko, S.S. Alekseev, I.M. Pan'kova, and L.S. Terranen. 1989. Long-term experiments on man's stay in a biological life-support system. Adv. Space Res. 9:65-71.

Hand, D.W. 1973a. Techniques for measuring $\mathrm{CO}_{2}$ assimilation in controlled environment enclosures. Acta Hort. 32:133-147.

Hand, D.W. 1973b. A null-balance method for measuring crop photosynthesis in an airtight, daylit controlled-environment cabinet. Agr. Meteorol. 12:259-270.

Jarvis, P.G. and A.P. Sandford. 1985. The measurement of carbon dioxide in air, p. 29-57. In: B. Marshall and F.I. Woodword (eds.). Instrumentation for environmental physiology. Cambridge Univ. Press, Cambridge, U.K.

Knight, S.L. 1992. Constructing specialized plant growth chambers for gasexchange research: Considerations and concerns. HortScience 27:767769.

Knight, S.L., C.P. Akers, S.W. Akers, and C.A. Mitchell. 1988. Minitron II systems for precise control of the plant growth environment. Photosynthetica 22:90-98

MacElroy, R.D. and J. Bredt. 1985. Concepts and future directions of CELSS. In: Controlled ecological life support system: Life support systems in space travel. NASA Conf. Publ. 2378.

McDermitt. D.K.. J.M. Norman. J.T. Davis. T.M. Ball, T.J. Arkebauer, J.M. Welles, and S.R. Roemer. 1989. CO response curves can be measured with a field-portable closed-loop photosynthesis system. Ann. Sci. For. 46(suppl.):416s-420s.

Mitchell, C.A. 1992. Measurement of photosynthetic gas exchange in controlled environments. HortScience 27:764-767.

Morison, J.I.L. and R.M. Gifford. 1984. Ethylene contamination of CO cylinders. Effects on plant growth in $\mathrm{CO}_{2}$ enrichment studies. Plant Physi o $1.75: 275-277$

Musgrave, R.B. and D.N. Moss. 1961. Photosynthesis under field conditions: I. A portable, closed system for determining net assimilation and respiration of corn. Crop. Sci. 1:37-41.

Prince, R.P. and W.M. Knott. 1989. CELSS breadboard project at the Kennedy Space Center. In: D.W. Ming and D.L. Henninger (eds.). Lunar base agriculture. Amer. Soc. Agron., Madison, Wis.

Prince. R.P., W.M. Knott, J.C. Saner, and S.E. Hilding. 1987. Design and performance of the KSC biomass production chamber. SAE Tech. Paper 871437, Soc. Automotive Eng. Conf., Seattle, July 1987.

Sager, J.C., C.R. Hargrove, R.P. Prince, and W.M. Knott. 1988. CELSS atmospheric control system. ASAE Paper 88-4018, Amer. Soc. Agr. Eng., St. Joseph, Mich.

Schwartzkopf, S.H. and P.E. Stofan. 1981. A chamber designed for closed ecological systems research. Amer. Soc. Mech. Eng. Publ. 81-ENAs-37.

von Cammerer, S. and G.D. Farquhar. 1981. Some relationships between the biochemistry of photosynthesis and the gas exchange of leaves. Planta $153: 376-387$

Wheeler, R.M., J.H. Drese, and J.C. Sager. 1991. Atmospheric leakage and condensate production in NASA's biomass production chamber. Effect of diurnal temperature cycles. NASA Tech. Memoran. 103819, Kennedy Space Center, Fla.

Wheeler, R.M., C.L. Mackowiak, T.W. Dreschel, J.C. Sager, R.P. Prince, W.M. Knott; C.R. Hinkle, and R.S. Strayer. 1990. System development and early biological tests in NASA's biomass production chamber. NASA Tech. Memoran. 103494, Kennedy Space Center, Fla.

Wheeler, R.M. and J.C. Sager. 1990. Carbon dioxide and water exchange rates by a wheat crop in NASA's biomass production chamber: Results from an 86-day study (January to April 1989). NASA Tech. Memoran. 102788, Kennedy Space Center, Fla. 